\title{
Selective serotonin reuptake inhibitor use during early pregnancy and congenital malformations: a systematic review and meta-analysis of cohort studies of more than 9 million births
}

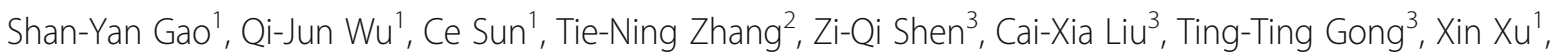
Chao Ji', Dong-Hui Huang', Qing Chang ${ }^{1}$ and Yu-Hong Zhao ${ }^{1 *}$

\begin{abstract}
Background: In 2005, the FDA cautioned that exposure to paroxetine, a selective serotonin reuptake inhibitor (SSRI) , during the first trimester of pregnancy may increase the risk of cardiac malformations. Since then, the association between maternal use of SSRIs during pregnancy and congenital malformations in infants has been the subject of much discussion and controversy. The aim of this study is to systematically review the associations between SSRIs use during early pregnancy and the risk of congenital malformations, with particular attention to the potential confounding by indication.
\end{abstract}

Methods: The study protocol was registered with PROSPERO (CRD42018088358). Cohort studies on congenital malformations in infants born to mothers with first-trimester exposure to SSRIs were identified via PubMed, Embase, Web of Science, and the Cochrane Library databases through 17 January 2018. Random-effects models were used to calculate summary relative risks (RRs).

Results: Twenty-nine cohort studies including 9,085,954 births were identified. Overall, use of SSRIs was associated with an increased risk of overall major congenital anomalies (MCAs, RR 1.11,95\% Cl 1.03 to 1.19) and congenital heart defects (CHD, RR 1.24, 95\% Cl 1.11 to 1.37). No significantly increased risk was observed when restricted to women with a psychiatric diagnosis (MCAs, RR 1.04, 95\% Cl 0.95 to 1.13; CHD, RR 1.06, 95\% Cl 0.90 to 1.26). Similar significant associations were observed using maternal citalopram exposure (MCAs, RR 1.20, 95\% Cl 1.09 to 1.31; CHD, RR 1.24, 95\% Cl 1.02 to 1.51), fluoxetine (MCAs, RR 1.17, $95 \% \mathrm{Cl} 1.07$ to $1.28 ; \mathrm{CHD}, 1.30,95 \% \mathrm{Cl} 1.12$ to 1.53 ), and paroxetine (MCAs, RR 1.18, 95\% Cl 1.05 to $1.32 ;$ CHD, RR $1.17,95 \% \mathrm{Cl} 0.97$ to 1.41) and analyses restricted to using women with a psychiatric diagnosis were not statistically significant. Sertraline was associated with septal defects (RR 2.69, 95\% Cl 1.76 to 4.10), atrial septal defects (RR 2.07, 95\% Cl 1.26 to 3.39), and respiratory system defects (RR 2.65, 95\% Cl 1.32 to 5.32 ).

Conclusions: The evidence suggests a generally small risk of congenital malformations and argues against a substantial teratogenic effect of SSRIs. Caution is advisable in making decisions about whether to continue or stop treatment with SSRIs during pregnancy.

Keywords: Antidepressant, Congenital malformations, Cohort studies, Pregnancy, Serotonin uptake inhibitors, Meta-analysis

\footnotetext{
* Correspondence: zhaoyh@sj-hospital.org

'Department of Clinical Epidemiology, Shengjing Hospital of China Medical

University, No. 36, San Hao Street, Shenyang, Liaoning, China

Full list of author information is available at the end of the article
}

(c) The Author(s). 2018 Open Access This article is distributed under the terms of the Creative Commons Attribution 4.0 International License (http://creativecommons.org/licenses/by/4.0/), which permits unrestricted use, distribution, and reproduction in any medium, provided you give appropriate credit to the original author(s) and the source, provide a link to the Creative Commons license, and indicate if changes were made. The Creative Commons Public Domain Dedication waiver (http://creativecommons.org/publicdomain/zero/1.0/) applies to the data made available in this article, unless otherwise stated. 


\section{Background}

Selective serotonin reuptake inhibitors (SSRIs) have become the first-line pharmaceuticals for the treatment of depression, anxiety, and other psychiatric disorders since they were introduced into the market [1]. About 63\% to $85 \%$ of pregnant women with exposure to antidepressant are treated with SSRIs [2-4]. SSRIs are thought to be effective for treating psychiatric disorders by increasing the synaptic bioavailability of the neurotransmitter serotonin (5-HT), which readily crosses the placenta and can affect certain kinds of cells and tissues during embryogenesis, which may result in certain congenital malformations, especially cardiac malformations [5-8]. In December 2005, the US Food and Drug Administration (FDA) cautioned that the use of paroxetine, as individual SSRI during the first trimester of pregnancy may increase the risk of cardiac malformations [9]. Since then, the associations between the use of SSRIs during pregnancy and the risk of congenital malformations in offspring have been the subject of much discussion and controversy [10].

The number of published meta-analyses regarding the associations between maternal use of SSRIs and congenital malformations has more than tripled during the last 5 years (20 meta-analyses to date). However, some of these studies produced conflicting results due to varying study designs and exposure times. Most inconsistently reported were congenital heart defects (CHD) (Additional file 1: Table S1). Furthermore, none of these meta-analyses attempted to comprehensively investigate the associations between the use of SSRIs and individual SSRIs and the risks of specific congenital malformations. Some of the previous meta-analyses [11-23] examined the risks of certain congenital malformations [overall major congenital anomalies (MCAs) and cardiac malformations] with maternal use of SSRIs and/or individual SSRIs. Other meta-analyses [24-28] examined the risks of specific (cardiac) malformations with the use of only one or two specific SSRIs. Reefhuis and colleagues [29] examined the risks of 15 congenital malformations categories with the use of individual SSRIs during early pregnancy; however, recall bias derived from case-control studies might have been inherent in those data. A large number of cohort studies were published recently that explore the aforementioned associations from Europe and other regions, but the results are still inconsistent [30-47].

Depression and anxiety have been associated with adverse pregnancy outcomes and health behaviors [48-50]. Thus, some researchers have expressed concerns that the underlying depression or psychiatric illness might increase the risks of congenital malformations in infants [51-53]. To the best of our knowledge, no previous meta-analyses have assessed potential confounding by indication (underlying psychiatric diagnosis) by comparing women using SSRIs vs. those with unmedicated psychiatric illness during the first trimester of pregnancy.

We performed a detailed systematic review and large-scale meta-analysis of current evidence from cohort studies to investigate whether there is any relationship between maternal use of SSRIs during early pregnancy and congenital malformations in infants. Particular attention is given to the potential for confounding by indication.

\section{Methods}

The report of this systemic review and meta-analysis followed the recommendations of the Preferred Reporting Items for Systematic Reviews and Meta-Analyses (PRISMA) group [54]. Before study selection, the protocol for this review was registered with PROSPERO (CRD42018088358).

\section{Data sources and searches}

PubMed, Embase, Web of Science, and The Cochrane Library were searched from database inception to 17 January 2018. The search strategy combined medical subject heading $(\mathrm{MeSH})$ and Embase subject heading (EMTREE) terms with other unindexed or free-text terms. Details of the full search strategy are provided in Additional file 2. Reference lists of retrieved articles and previous systematic and narrative reviews were searched manually to retrieve all relevant documents. No language restrictions were imposed.

\section{Study selection}

Cohort studies or randomized controlled trials that reported original data were eligible for inclusion if they reported any congenital malformations in infants born to mothers with any exposure to SSRIs or individual SSRIs (citalopram, fluoxetine, paroxetine, sertraline, escitalopram, or fluvoxamine) during the first trimester, had a comparison group that included pregnant women who were not exposed to any antidepressants and/or teratogens (folic acid antagonists, angiotensin-converting enzyme inhibitors, anticonvulsants, coumarin derivatives, and retinoids), and, if a risk estimate was not reported, provided necessary distribution of exposure, non-exposure, cases, and non-cases, from which a risk estimate could be calculated.

The titles and abstracts of retrieved articles were evaluated by two independent reviewers (S-YG and CS). The full texts of potentially eligible studies that seemed to meet the inclusion criteria were then obtained and independently reviewed by the two reviewers. Any disagreements were identified and resolved by discussion or by consultation with a third reviewer (Q-JW). If data were duplicated in more than one study, we included the study with the largest number of cases. 


\section{Data extraction}

A standardized, pre-designed spreadsheet was used for data extraction from the included studies. The study quality and synthesis of evidence were assessed. The following data were extracted into the spreadsheet: first author, publication year, geographic location, study period, data source, sample size (cases and cohorts), types of birth, definition of outcome, outcome with their risk estimates and 95\% confidence intervals (CIs), and adjusted confounders. Congenital malformations were identified and defined according to the European Surveillance of Congenital Anomalies (EUROCAT) Guide 1.3 and ICD-10 and ICD-9 codes (Additional file 3: Table S1). The primary outcomes of interest were overall MCAs and specific CHD. The secondary outcomes of interest were other system-specific malformations (nervous system defects; eye defects; ear, face, and neck defects; respiratory system defects; orofacial cleft; digestive system defects; urogenital system defects; urinary system defects; genital system defects; musculoskeletal system defects; limb; and abdominal wall defects. Two reviewers (T-NZ and Z-QS) extracted data independently; any disagreements were resolved by discussion with a third reviewer (S-YG) where necessary.

For a study [36] that reported a different follow-up duration, the estimate of the follow-up duration during the first 6 years of life was extracted. For studies [31, 40, $44,45,47,55-61]$ that did not report any adjusted risk estimate, we used the crude risk estimate. If a study lacked required data, they were requested by contacting the study authors by email.

\section{Risk of bias assessment}

We used the Newcastle-Ottawa scale [62] to assess the risk of bias of cohort studies, which included studies based on the selection of study participant groups (four stars), the comparability of study groups (two stars), and the ascertainment of outcome (three stars). Studies were considered to have low risk of bias if they achieved a full rating in at least two categories of selection, comparability, or outcome assessment [63].

\section{Statistical analysis}

For a study [64] that separately reported the risk estimates of SSRIs but did not report combined estimates, the effective count method proposed by Hamling et al. [65] was used to recalculate the effect estimate. Another study [56] reported results separately (but not combined) for CHD (bulbus cordis anomalies and anomalies of cardiac septal closure and other congenital anomalies of heart), nervous system malformations (spina bifida and other congenital anomalies of nervous system), digestive system defects (cleft palate and cleft lip, other congenital anomalies of upper alimentary tract, and other congenital anomalies of digestive system), and musculoskeletal system defects (certain congenital musculoskeletal deformities, other congenital musculoskeletal anomalies, and other congenital anomalies of limbs); here, the results were pooled using a fixed-effect model to obtain an overall combined estimate before combining these estimates with the remaining studies (Additional file 3: Table S1). Similar analyses also were performed for limb defects (limb reduction and clubfoot) $[31,34]$. If the selected study did not include a risk estimate, the unadjusted risk estimate and the 95\% CI were calculated from the raw data for simplicity $[31,38$, $44,45,57,59,61,66]$. Because the odds ratio is an excellent approximation of the risk ratio in the case of rare outcomes, the results were referred to as relative risks (RRs) [67]; therefore, all results were reported as RR for simplicity. Estimates were pooled using the DerSimonian and Laird random-effects model to calculate summarized RRs and 95\% CI [68].

We used the $I^{2}$ statistic to assess heterogeneity in effect measures between the studies. $I^{2}$ values of 25 , 50 , and $75 \%$ were considered to represent low, moderate, and high heterogeneity, respectively [69]. If $\geq 8$ studies were available, potential sources of heterogeneity were explored by conducting subgroup analyses according to the following parameters: study quality (high risk vs. low risk), geographic location (Europe vs. Northern America or other regions), and adjustment for potential confounders (adjusted vs. unadjusted) including maternal age, socioeconomic status, smoking, alcohol drinking, body mass index (BMI) during pregnancy, pregnancy complications, and parity. Heterogeneity between subgroups was evaluated by meta-regression analysis. The potential for publication bias was examined through Begg's and Egger's tests [70, 71]. To determine the influence of an individual study in each main analysis of the estimated RR, we conducted a sensitivity analysis that recalculated the pooled effect by omitting one study at a time. Analyses were performed with Stata version 11.0 (StataCorp, College Station, TX). A two-tailed $P$ value less than 0.05 was considered as statistically significant.

\section{Results}

\section{Search results}

We identified 10,919 potentially eligible articles in PubMed, Embase, Web of Science, and The Cochrane Library. Two additional studies were identified in a manual search of the reference lists. The titles and abstracts were screened, and 79 articles qualified for full-text review (Fig. 1). The authors of two studies failed to respond to requests for additional data. Finally, 29 cohort studies (published between 1996 and 2017) providing 649 data points that contributed to the quantitative 


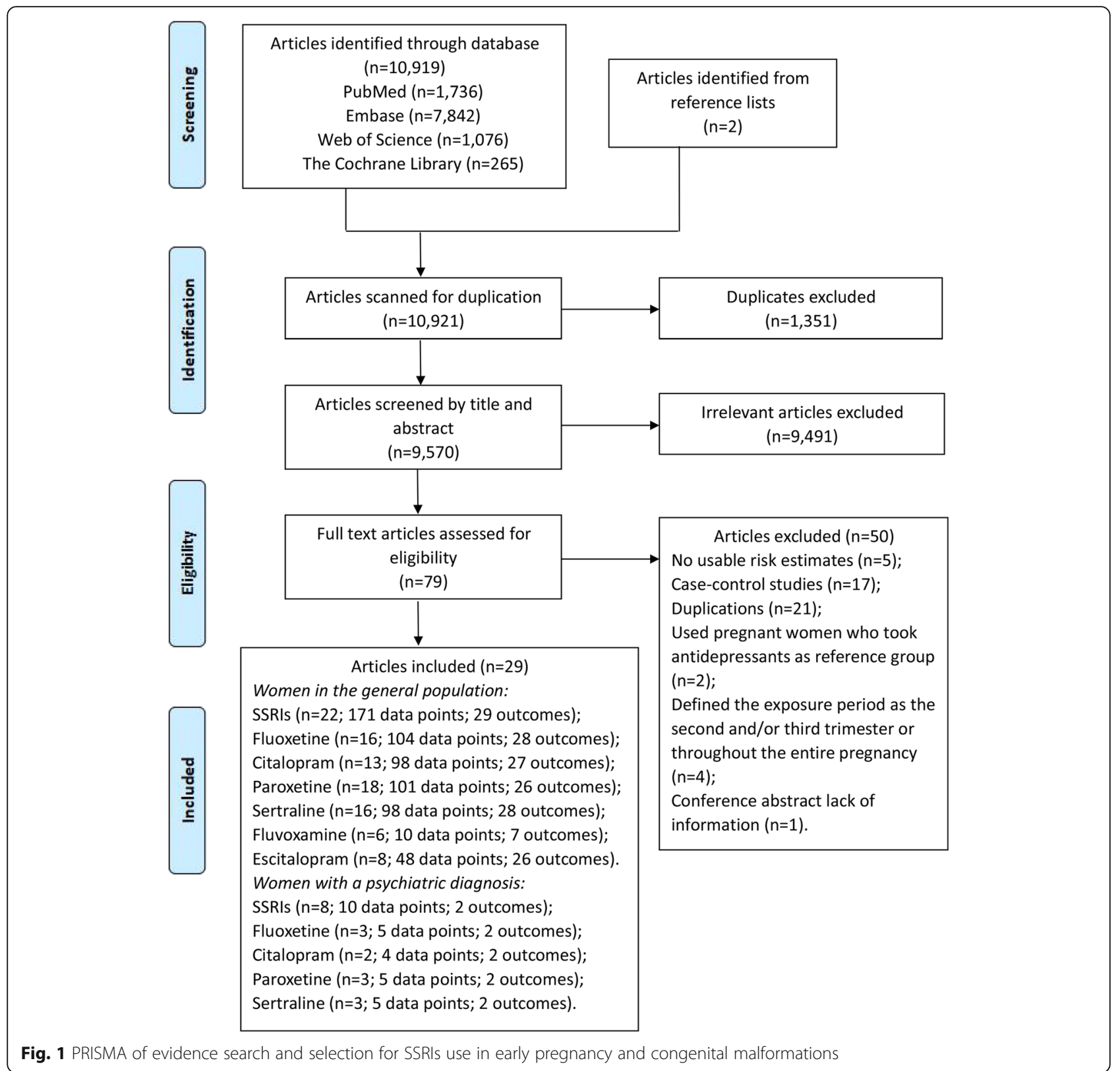

synthesis met all inclusion and exclusion criteria, which included a total of 9,085,954 individuals for analysis. These included 25 studies focused on women in the general population, 8 studies focused on women with a psychiatric disorder, and 6 studies focused on both; $7,926,215$ untreated pregnant women without psychiatric disorders, 1,916,076 SSRI-untreated women with psychiatric disorders, and 59,894 SSRI-treated women with psychiatric disorders; 7,590,399 individuals from Europe (15 studies), 1,206,094 from North America (10 studies), and 289,461 from Japan and Israel (4 studies). The key characteristics of the included studies are presented in Additional file 3: Table S2.

\section{Bias assessment}

Analysis of the included studies using Newcastle-Ottawa criteria indicated that 23 studies were low risk and 6 were high risk for bias. All studies achieved a total score of 4 to 9 (median $=8)$ (Additional file 3: Table S3).

\section{Exposure to SSRIs}

\section{Risk of major congenital anomalies}

Nine studies [34, 37-40,43, 60, 61, 72] for the comparison of women receiving SSRIs versus women in the general population were included for this analysis. The pooled RR was 1.11 (95\% CI 1.03 to $1.19, I^{2}=38.4 \%$, $P=0.11$, Figs. 2 and 3, Additional file 3: Table S4), with no 


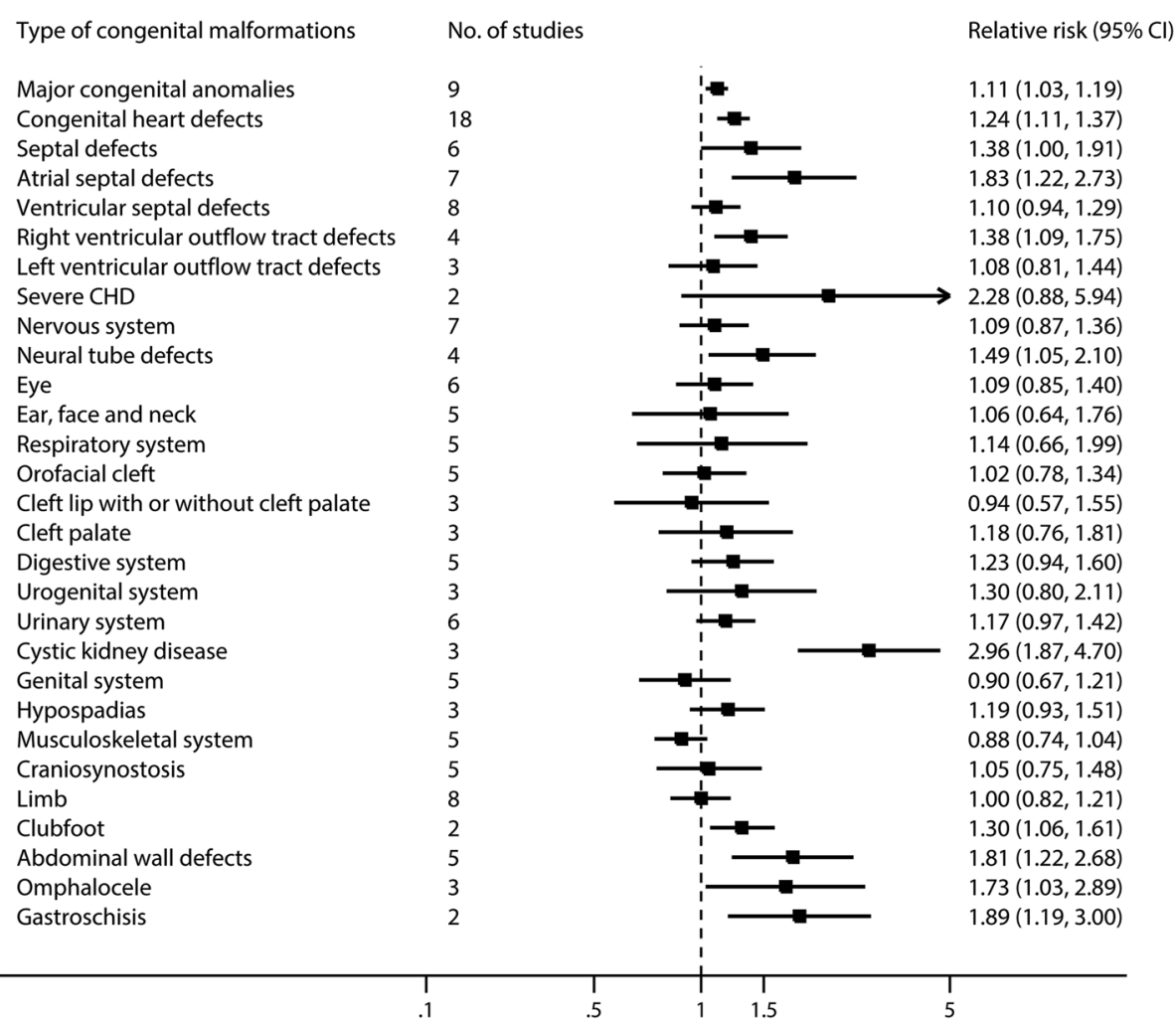

Fig. 2 Risk of congenital malformations in infants, according to maternal exposure to SSRIs. Relative risks and 95\% confidence intervals are presented to show the risk of congenital malformations among infants born to women with exposure to SSRIs during the first trimester, as compared with the risk among infants born to women in the general population without such exposure. SSRIs, selective serotonin reuptake inhibitors

evidence of publication bias (Begg's $P=0.92$, Eggers's $P=0.83$ ). No significantly increased risk was observed when restricted to women with a psychiatric diagnosis (RR $1.04,95 \%$ CI 0.95 to $1.13, I^{2}=2.5 \%, P=0.38$, Fig. 3) [2, 33, 37, 72].

\section{Risk of specific congenital heart defects}

Eighteen studies [31, 32, 34-40, 42-44, 46, 55, 56, 58, $61,72]$ in the general population were included for this analysis. The pooled RR was 1.24 (95\% CI 1.11 to 1.37 , $I^{2}=59.0 \%, P=0.001$, Figs. 2 and 4, Additional file 3: Table S4), with no evidence of publication bias (Begg's $P$ $=0.23$, Eggers's $P=0.45$ ). No significantly increased risk was observed when restricted to women with a psychiatric diagnosis (RR 1.06, 95\% CI 0.90 to $1.26, I^{2}=33.9 \%$, $P=0.18$, Fig. 4) [31, 37, 41, 55, 64, 72].

Maternal use of SSRIs during the first trimester was associated with an increased risk in septal defects [36, $37,40,42,43,72$ ] (RR $1.38,95 \%$ CI 1.00 to $1.91, I^{2}=$ $67.4 \%, P=0.009$ ), atrial septal defects (ASD) [31, 35, 37, $39,40,61,72$ ] (RR $1.83,95 \%$ CI 1.22 to $2.73, I^{2}=72.0 \%$, $P=0.002)$, and right ventricular outflow tract defects (RVOTD) [34, 39, 55, 72] (RR 1.38, 95\% CI 1.09 to 1.75 , $I^{2}=33.0 \%, P=0.21$ ) (Figs. 2 and 5; Additional file 3:
Table S4). No evidence of publication bias was detected in any of these studies (all $P>0.05$ ).

\section{Risk of other system-specific malformations}

Maternal use of SSRIs during the first trimester was associated with an increased risk of neural tube defects [31, $37,39,46]$ (RR $1.49,95 \%$ CI 1.05 to $2.10, I^{2}=0, P=0.43$ ), cystic kidney disease $[34,40,46]$ (RR 2.96, 95\% CI 1.87 to $4.70, I^{2}=0, P=0.81$ ), clubfoot $[31,34]$ (RR $1.30,95 \% \mathrm{CI}$ 1.06 to $\left.1.61, I^{2}=0, P=0.65\right)$, abdominal wall defects [30, 31, 37, 46, 72] (RR 1.81, 95\% CI 1.22 to 2.68, $\left.I^{2}=0, P=0.86\right)$, omphalocele $[31,34,39]$ (RR 1.73, $95 \%$ CI 1.03 to $2.89, I^{2}=0, P=0.73$ ), and gastroschisis [31, 34] (RR 1.89, 95\% CI 1.19 to $3.00, I^{2}=0, P=0.56$ ) (Fig. 2, Additional file 3: Table S4).

\section{Exposure to individual SSRIs Citalopram}

Eight studies [34, 37, 39, 40, 43, 60, 61, 72] in the general population provided data for MCAs in infants. The pooled RR was 1.20 (95\% CI 1.09 to 1.31 , $I^{2}=13.4 \%, P=0.33$ ), with no evidence of publication bias (Begg's $P=0.54$, Eggers's $P=0.77$ ). No significantly increased risk was observed when restricted to 
Study

Women in the general population

Furu 2015

Ban 2014

Jimenez-Solem 2012

Nordeng 2012

Colvin 2011

Malm 2011

Pedersen 2009

Einarson 2009

Oberlander 2008

Subtotal $(I-$ squared $=38.4 \%, p=0.113$ )

Women with a psychiatric diagnosis

Berard 2017

Malm 2015

Ban 2014

Jimenez-Solem 2012

Subtotal $(I-$ squared $=2.5 \%, p=0.380)$

NOTE: Weights are from random effects analysis
Relative risk $(95 \% \mathrm{Cl})$ Weight (\%)

$1.13(1.06,1.20) \quad 27.27$

$1.01(0.88,1.17) \quad 14.46$

$1.33(1.16,1.53) \quad 14.94$

$1.07(0.60,1.91) \quad 1.45$

$1.05(0.87,1.27) \quad 10.02$

$1.08(0.96,1.22) \quad 17.41$

$1.21(0.91,1.62) \quad 5.17$

$\rightarrow 1.39(0.78,2.51) \quad 1.42$

$0.91(0.73,1.14) \quad 7.86$

$1.11(1.03,1.19) \quad 100.00$

$1.07(0.93,1.22) \quad 39.29$

$1.03(0.88,1.20) \quad 30.39$

$0.93(0.78,1.11) \quad 23.66$

$1.27(0.91,1.78) \quad 6.66$

$1.04(0.95,1.13) \quad 100.00$

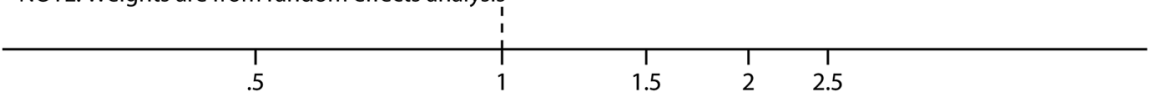

Fig. 3 Risk of major congenital anomalies in infants, according to maternal exposure to SSRls. Relative risks and 95\% confidence intervals are presented to show the risk of major congenital anomalies among infants born to women with exposure to SSRIs during the first trimester, as compared with the risk among infants born to women without such exposure. SSRIs, selective serotonin reuptake inhibitors

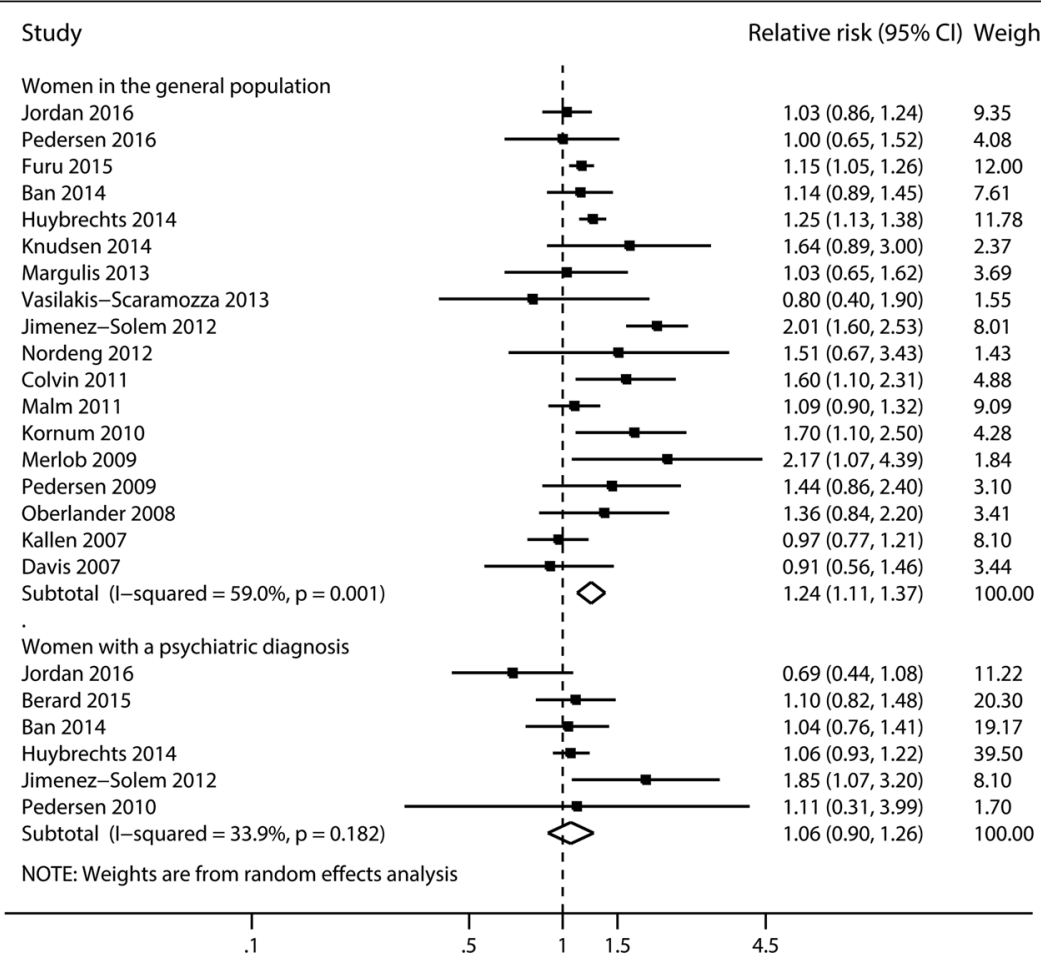

Fig. 4 Risk of congenital heart defects in infants, according to maternal exposure to SSRIs. Relative risks and 95\% confidence intervals are presented to show the risk of congenital heart defects among infants born to women with exposure to SSRIs during the first trimester, as compared with the risk among infants born to women without such exposure. SSRIs, selective serotonin reuptake inhibitors 


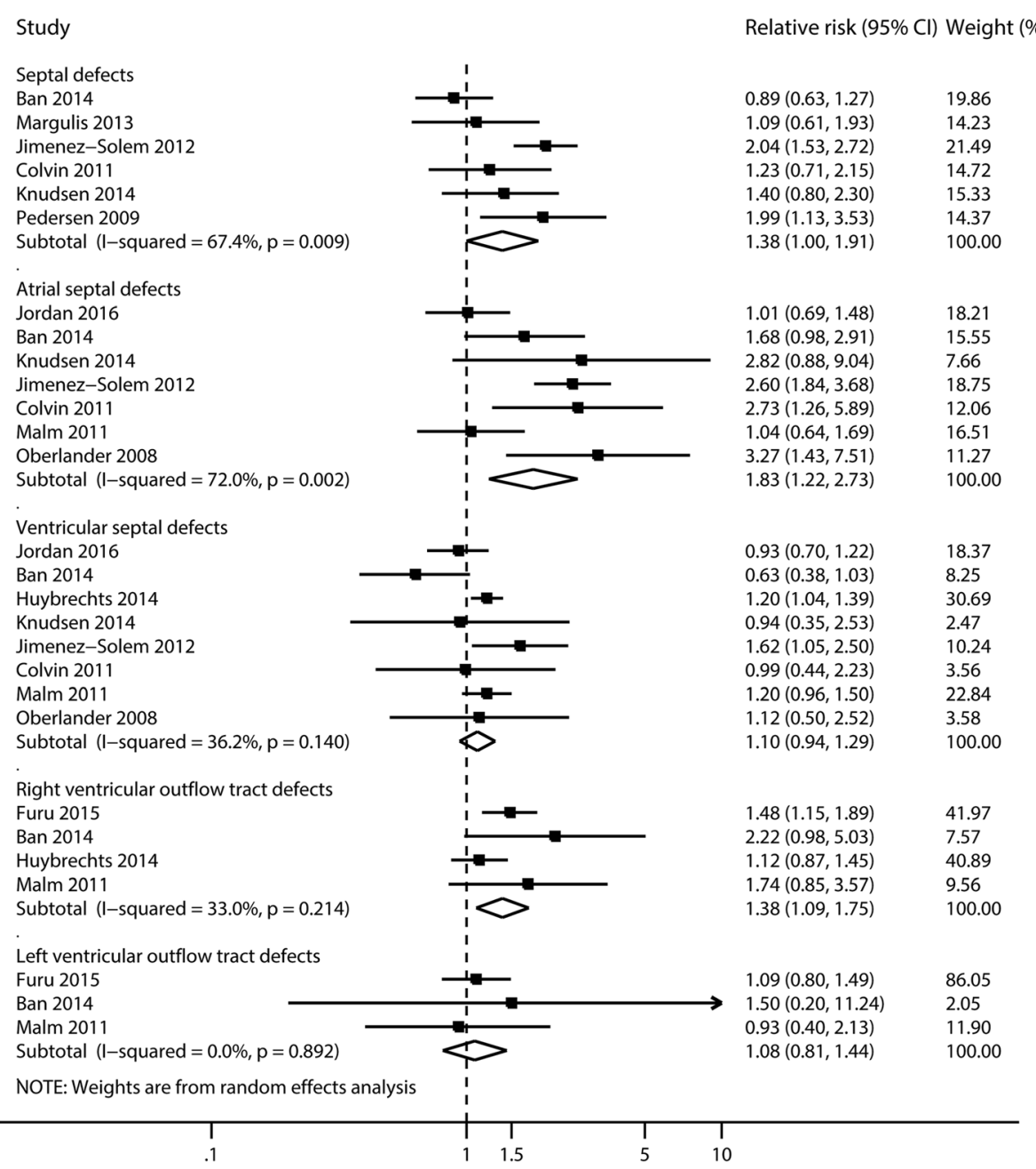

Fig. 5 Risk of septal defects in infants, according to maternal exposure to SSRIs. Relative risks and 95\% confidence intervals are presented to show the risk of septal defects among infants born to women with exposure to SSRIs during the first trimester, as compared with the risk among infants born to women in the general population without such exposure. SSRIs, selective serotonin reuptake inhibitors

women with a psychiatric diagnosis (RR $1.17,95 \% \mathrm{CI}$ 0.84 to $1.62, I^{2}=66.0 \%, P=0.09$ ) $[2,72]$ (Additional file 3: Table S5, Additional file 4).

Eleven studies [31, 34, 37, 39, 40, 42-44, 46, 61, 72] provided data for CHD in infants in the general population. The pooled RR was 1.24 (95\% CI 1.02 to $1.51, I^{2}=$ $52.5 \%, P=0.02$ ), with no evidence of publication bias (Begg's $P=0.23$, Eggers's $P=0.32$ ). No significantly increased risk was observed when restricted to women with a psychiatric diagnosis (RR $1.08,95 \%$ CI 0.75 to $\left.1.56, I^{2}=0, P=0.75\right)[2,72]$ (Additional file 3: Table S5, Additional file 5).

Citalopram use during the first trimester was associated with an increased risk of septal defects [37, 40, 42, 43] (RR $1.81,95 \%$ CI 1.22 to $2.68, I^{2}=0, P=0.55$ ), RVOTD [34, 39] (RR $1.59,95 \%$ CI 1.08 to $2.35, I^{2}=0, P=0.54$ ), eye defects [31, 37, 40, 72] (RR 2.00, 95\% CI 1.13 to $3.54, I^{2}=$ $0, P=0.55)$, urinary system defects $[31,37,40,72](R R$
1.72 , $95 \% \mathrm{CI} 1.27$ to $\left.2.33, I^{2}=0, P=0.72\right)$, and hypospadias [31, 34] (RR 1.87, 95\% CI 1.23 to $2.83, I^{2}=0, P=0.43$ ) (Additional file 3: Table S5).

\section{Fluoxetine}

Eleven studies [34, 37-40, 43, 45, 57, 60, 61, 72] in the general population provided data for MCAs in infants. The pooled RR was 1.17 (95\% CI 1.07 to $1.28, I^{2}=0, P=0.50$ ), with no evidence of publication bias (Begg's $P=0.28$, Eggers's $P=0.62$ ). No significantly increased risk was observed when restricted to women with a psychiatric diagnosis (RR 0.84, 95\% CI 0.67 to $1.05, I^{2}=0, P=0.83$ ) $[2,72]$ (Additional file 3: Table S6, Additional file 6).

Fourteen studies [31, 34, 37-40, 42-46, 55, 61, 72] provided data for CHD in infants in the general population. The pooled RR was 1.30 (95\% CI 1.12 to $1.53, I^{2}=$ $29.3 \%, P=0.14$ ), with no evidence of publication bias (Begg's $P=0.23$, Eggers's $P=0.32$ ). No significantly 
increased risk was observed when restricted to women with a psychiatric diagnosis (RR 0.94, 95\% CI 0.65 to 1.37, $I^{2}=41.9 \%, P=0.18$ ) $[2,55,72]$ (Additional file 3: Table S6, Additional file 7).

Fluoxetine use during the first trimester was associated with an increased risk of septal defects [37, 40, 42, 43] (RR $1.65,95 \%$ CI 1.02 to $2.67, I^{2}=0, P=0.99$ ), RVOTD [34, $39,55]$ (RR $1.63,95 \%$ CI 1.11 to $2.41, I^{2}=18.0 \%, P=0.30$ ), neural tube defects [31, 37, 39] (RR 2.28, 95\% CI 1.28 to $\left.4.06, I^{2}=0, P=0.76\right)$, and ear, face, and neck defects [31, 40] (RR 3.45, 95\% CI 1.28 to $9.29, I^{2}=0, P=0.41$ ) (Additional file 3: Table S6).

\section{Paroxetine}

Eleven studies [34, 37-40, 43, 45, 47, 60, 61, 72] provided data for MCAs in infants in the general population. The pooled RR was 1.18 (95\% CI 1.05 to $1.32, I^{2}=$ $0, P=0.64$ ), with no evidence of publication bias (Begg's $P=0.09$, Eggers's $P=0.14$ ). No significantly increased risk was observed when restricted to women with a psychiatric diagnosis (RR $1.17,95 \%$ CI 0.97 to $1.41, I^{2}=0$, $P=0.34$ ) $[2, \quad 72] \quad$ (Additional file 3: Table S7, Additional file 8).

Sixteen studies $[31,34,37-40,42-45,55,56,61,66$, 72] in the general population provided data for CHD in infants. The pooled RR was 1.35 (95\% CI 1.19 to 1.53 , $I^{2}=0, P=0.71$ ), with no evidence of publication bias (Begg's $P=0.69$, Eggers's $P=0.21$ ). No significantly increased risk was observed when restricted to women with a psychiatric diagnosis (RR $1.27,95 \%$ CI 0.89 to $1.80, I^{2}=72.3 \%, P=0.03$ ) $[2,55,72]$ (Additional file 3 : Table S7, Additional file 9).

Paroxetine use during the first trimester was associated with an increased risk of RVOTD [34, 39, 55] (RR 2.15, 95\% CI 1.04 to $4.44, I^{2}=67.0 \%, P=0.049$ ), eye defects $[31,56,72]$ (RR 2.26, 95\% CI 1.26 to 4.04 , $I^{2}=0, P=0.53$ ), and cleft palate [31, 39] (RR 2.82, 95\% CI 1.26 to $6.32, I^{2}=0, P=0.83$ ) (Additional file 3: Table S7).

\section{Sertraline}

Nine studies [34, 37-40,43, 60, 61, 72] provided data for MCAs in infants. The pooled RR was 1.10 (95\% CI 0.99 to $1.22, I^{2}=0, P=0.69$ ), with no evidence of publication bias (Begg's $P=0.92$, Eggers's $P=0.85$ ). No significantly increased risk was observed when restricted to women with a psychiatric diagnosis (RR 1.12, 95\% CI 0.87 to $1.44, I^{2}=0, P=0.79$ ) [2, 72] (Additional file 3: Table S8, Additional file 10).

Thirteen studies [31, 34, 37-40, 42-44, 46, 55, 61, 72] provided data for $\mathrm{CHD}$ in infants. The pooled RR was $1.42\left(95 \%\right.$ CI 1.12 to $1.80, I^{2}=63.9 \%, P=0.001$ ), with no evidence of publication bias (Begg's $P=0.50$, Eggers's $P=0.26$ ). No significantly increased risk was observed when restricted to women with a psychiatric diagnosis (RR 1.12, 95\% CI 0.92 to $1.35, I^{2}=0, P=0.80$ ) $[2,55,72]$ (Additional file 3: Table S8, Additional file 11).

Sertraline use during the first trimester was associated with an increased risk of septal defects [37, 40, 42, 43] (RR $2.69,95 \%$ CI 1.76 to $4.10, I^{2}=16.8 \%, P=0.31$ ), ASD [31, 37, 39, 40] (RR 2.07, 95\% CI 1.26 to 3.39 , $\left.I^{2}=0, P=0.54\right)$, respiratory system defects $[37,39,40$, 72] (RR 2.65, 95\% CI 1.32 to $5.32, I^{2}=0, P=0.45$ ), limb defects $[31,34,37,72]$ (RR $1.42,95 \%$ CI 1.03 to $1.95, I^{2}=0, P=0.54$ ), and clubfoot $[31,34]$ (RR 1.72, 95\% CI 1.11 to $2.65, I^{2}=0, P=0.77$ ) (Additional file 3: Table S8).

\section{Escitalopram/fluvoxamine}

Maternal use of escitalopram during the first trimester was associated with an increased risk of clubfoot [31] (RR 2.18, 95\% CI 1.16 to 4.08), abdominal wall defects [31] (RR 3.52, 95\% CI 1.56 to 7.93), and gastroschisis [31] (RR 3.95, 95\% CI 1.46 to 10.68) (Additional file 3: Table S9). There was no statistically significant association between first-trimester exposure to fluvoxamine and MCAs [34, 39, 60, 61] (RR 0.77, 95\% CI 0.49 to $1.21, I^{2}=0, P=0.79$, Additional file 3: Table S10).

\section{Subgroup and sensitivity analyses}

The results of subgroup and meta-regression analyses are presented in Additional file 3: Table S11-S15. Subgroup analyses indicated that the low risk of bias studies and European studies were generally consistent with the main results; however, they were not all statistically significant. No statistically significant source of heterogeneity was identified in meta-regression analyses. The sensitivity analysis omitted one study at a time, which showed the results appeared to be robust to the influence of individual studies. By contrast, the pooled RR of MCAs was 1.06 with SSRIs (95\% CI 0.85 to 1.32 , $\left.I^{2}=0, P=0.67\right)$ after excluding the study by Huybrechts et al. [55].

\section{Discussion}

This comprehensive systemic review and meta-analysis of cohort studies including more than nine million births found generally small increased risks in 18 of 29 congenital malformations categories in infants born to mothers with exposure to SSRIs and individual SSRIs during early pregnancy, especially for MCAs and CHD. We found the RRs for the association between use of SSRIs and outcomes were lower in the restricted cohorts. Though the 95\% CIs of the comparisons made between studies in general population and studies in mothers with a psychiatric diagnosis contained an overlap, we still cannot exclude the possibility of confounding by indication. 


\section{SSRIs and congenital malformations}

We identified a small but significant association between maternal use of SSRIs during the first trimester and MCAs in infants. This observed increase was consistent with the results of previous meta-analyses $[15,19]$ However, the association was attenuated after controlling for psychiatric diagnosis. Although the effects of SSRIs could never be completely separated from a psychiatric illness itself, such estimates are likely to be influenced by potential confounding by indication. Jimenez-Solem and colleagues [37] first differentiated between the consequences of SSRI use and the underlying disease, and found an increased risk of MCAs among infants born to women who took SSRIs during the first trimester, whereas the correlation was not significant for women who paused their use of SSRIs during the first trimester in a nationwide cohort study. Ban and colleagues [72] compared risks between pregnant women with medicated and unmedicated depression based on a population-based cohort study. Although results for MCAs were not statistically significant, the point estimate slightly decreased in comparison with pregnant women treated with SSRIs.

There was an association between first-trimester exposure to SSRIs and the risk of CHD. Some biological evidence possibly supports the observed increase $[8,73]$, but the results were inconsistent in three meta-analyses $[14,15,19]$. This difference is probably due to variations in sample size, study design, and time of exposure. The meta-analysis by Wang and colleagues [14] included four population-based cohort studies enrolling $1,996,519$ participants and found no significant associations between the use of SSRIs and heart defects (Additional file 1: Table S1). In recent years, fourfold population-based cohort studies including nearly eight million participants have been conducted to examine the aforementioned relationship, and the results were consistent with our primary results (our unreported data). Myles and colleagues [15] synthesized evidence from nine cohort studies combined with case-control studies; however, high heterogeneity might have been inherent in those data. Nikfar and colleagues [19] assessed the risk of cardiovascular malformations with the use of SSRIs during pregnancy, but not during the first trimester. Similarly, the association was markedly attenuated after controlling for psychiatric diagnosis.

\section{Individual SSRIs and congenital malformations Citalopram}

The observed increase in MCAs and CHD with maternal use of citalopram during the first trimester was inconsistent with all previous meta-analyses [11, 12, 14, 15]. A recent meta-analysis by Kang and colleagues [11], including five cohort studies and one case-control study, reported no significant associations between exposure to citalopram and the risk of CHD during pregnancy. However, over twofold cohort studies were eligible for inclusion in our analysis. Data for 2.3 million births from a previous cohort study [34] were re-analyzed by an aggregate meta-analysis by Selmer and colleagues [12]; this cohort study was included in our meta-analysis. Results between the meta-analysis and the included study were similar regarding the association of citalopram use and $\mathrm{CHD}$. Our findings regarding the effect of citalopram use on neural tube defects and hypospadias were inconsistent with the study by Reefhuis and colleagues [29], which used Bayesian analysis to combine summarized results from published literature with data from the US National Birth Defects Prevention Study.

\section{Fluoxetine}

The main results of this meta-analysis of fluoxetine use during early pregnancy were consistent with our previous study [26] and a recent meta-analysis by Selmer and colleagues [12]. Our data on fluoxetine-associated ventricular septal defects (VSD) and RVOTD were consistent with the study of Reefhuis and colleagues [29]. Our data also showed significant associations between fluoxetine use and the risk of system-specific malformations (neural tube defects and ear, face, and neck defects). However, these results require corroboration due to the limited number of individual studies.

\section{Paroxetine}

Our data show a significant association between the use of paroxetine and the risks of MCAs and CHD. The results were consistent with a recent meta-analysis by Berard and colleagues [27], but were inconsistent with a previous meta-analysis by $\mathrm{Bar}-\mathrm{Oz}$ and colleagues [22]. Bar- $\mathrm{Oz}$ and colleagues conducted the analysis in 2007, and thus only included three cohort and case-control studies. Two meta-analyses assessed the risk of system-specific malformations from exposure to paroxetine and yielded inconsistent results due to the varying study design. One meta-analysis of cohort and cases studies [27] identified an increased risk of septal defects and ASD with paroxetine use; the other meta-analysis of case-control studies [29] identified an increased risk of ASD, gastroschisis, and omphalocele with paroxetine use (but not cleft palate or hypospadias).

\section{Sertraline}

Although the findings of this meta-analysis were consistent with our previous study [25], our data regarding the association of sertraline use with septal defects were inconsistent with the results of Reefhuis and colleagues [29]. Our data also showed significant associations between sertraline use and the risk of system-specific 
malformations (respiratory system defect, limb defect, and clubfoot). These results require corroboration due to the limited number of individual studies.

\section{Escitalopram}

The main results of this meta-analysis were consistent with previous meta-analyses [12, 29] regarding the risks of CHD and septal defects from exposure to escitalopram during early pregnancy. One of our included studies [31] reported statistically significant associations between escitalopram use and the risk of system-specific malformations (limb defect, clubfoot, abdominal wall defects, and gastroschisis) in three population-based cohorts that included 519,117 fetuses and infants.

\section{Potential mechanism}

Potential biological mechanisms of SSRI use and the increased risk of congenital malformations is based on studies of drug metabolite levels in cord blood in human [74]. In vitro, a growing body of evidence has suggested that the neurotransmitter serotonin $(5-\mathrm{HT})$ plays a crucial role as a signaling molecule in cardiogenesis $[8,75]$. Consequently, disruption of the 5-HT signaling caused by the use of SSRIs may result in several different types of CHD [73, 76].

\section{Strengths and limitations of the study}

Our study has several strengths. First, this meta-analysis of current evidence from cohort studies includes the largest sample size (more than nine million births) analyzed to date and combines the results with the most comprehensive data related to associations between the use of SSRIs and all individual SSRIs during early pregnancy and the risks of 29 categories of congenital malformations. Second, this meta-analysis pays particular attention to the potential confounding by indication. Third, for ethical reasons, there are no randomized controlled trials; therefore, the quality of evidence from cohort studies could provide clinicians and pregnant women with a reference in clinical practice.

There are limitations in our meta-analysis related to evidence synthesis and quality. First, the definition of outcomes varied among studies, particularly the definition of CHD, which could contribute to the high heterogeneity in our study. CHD has a specific definition and coding in the EUROCAT guide, but not in the ICD codes; however, most of the individual studies defining outcomes were based on ICD codes such as ICD-10 and ICD-9 (Additional file 3: Table S1-S2). We also failed to find any specific coding in either the ICD codes or EUROCAT subgroups related to MCAs, septal defects, RVOTD, and left ventricular outflow tract defects. Furthermore, the definitions of outcomes might depend on the authors of individual studies. For example, Ban and colleagues [72] defined septal defects as ASD, VSD, and atrioventricular septal defects, whereas Pedersen and colleagues [43] defined the defects as ASD and VSD. Additionally, the follow-up duration may also be a potential source of heterogeneity. On the one hand, some types of CHD (e.g., VSDs) may be self-healing [77]. On the other hand, due to the serious malformations are usually symptomatic with early detection, whereas milder malformations are sometimes identified at later age [36].

Second, the majority of individual studies only included live births. Stillbirth, spontaneous abortion, or induced abortion caused by severe malformations [78, 79] were not always recorded or observable and would have been missed, which could introduce selection bias and underestimate the strength of the associations between the use of SSRIs during early pregnancy and congenital malformations in infants [80]. The restriction of results according to different data sources also could also result in potential bias. The pooled effects of this study were dominated by record-linkage studies. However, data collected from prescription registries, dispensation registries, or drug reimbursement registries that rely on dispensed prescription information to determine maternal use of SSRIs would lead to misclassification of exposure $[81,82]$. The dispensing of SSRIs may not always precisely reflect the specific time of exposure or verify that SSRIs were actually taken as prescribed. Selection bias presents a potential limitation in teratology information service studies, as women recruited during early pregnancy who feel the need for counseling about the teratogenic potential of SSRIs may be at higher risk than those who have no concerns [83].

Third, the event rate of congenital malformations in infants is very low, and individual studies may not have consistently adjusted for potential confounders. Therefore, we included adjusted or unadjusted risk estimates in our meta-analysis. Unadjusted risk estimates should be interpreted with caution, but the main results were still robust after removing crude risk estimates in the sensitivity analysis. Due to the lack of information on other potential confounders such as folic acid supplementation and familial-related factors, we could not fully rule out the possibility of residual confounding. For example, the study by Furu and colleagues [34] reported results from sibling design in addition to the full cohort. The results of sibling-controlled analyses showed attenuated risk compared with the full cohort. Thus, the small observed increased risk could be explained by familial-related factors or other lifestyle-related factors not adjusted for. In addition, we lacked information about the restricted cohorts regarding severity of disease. Eliminating the potential teratogenicity of SSRIs from a 
potential effect of the underlying psychiatric diagnoses remains a challenge.

Fourth, as we could not obtain an estimate for the incidence of MCAs and CHD events in the general population or in women with a psychiatric diagnosis, we could not provide an absolute risk increase of MCAs and CHD associated with exposure to SSRIs in the general population and in women with a psychiatric diagnosis. However, we obtained some examples from the published studies to give a suggestion of the increased absolute risk. Ban and colleagues [72] reported that children born to women with diagnosed depression unmedicated in early pregnancy had higher absolute risks of overall MCAs than children of mothers with no depression (absolute risk increase: 15 per 10000 births). Futhermore, Alwans et al. and Huybrechts et al. $[55,84]$ found a small increase in the absolute risk of CHD with exposure to SSRIs. Although the absolute risk of MCAs and CHD were highly likely to remain small, it is still of concern to pregnant women.

Fifth, it should be recognized that the implicated system-specific malformations and controlled psychiatric diagnosis studies are rare. The small number of included studies limited the statistical power of the study, which limited our ability to perform subgroup analyses to further investigate these issues and interpret the results. There was insufficient evidence to estimate fetal outcomes for the dosage of SSRIs use during pregnancy. Thus, we were unable to conduct a dose-response analysis.

Finally, since the study focused on non-exposure, i.e., pregnant women who were not exposed to any antidepressants and/or teratogens, rather than pregnant women who were exposed to other individual SSRIs, we could not determine if any of the individual SSRIs was preferable over others.

\section{Conclusions}

The results of this meta-analysis highlight the complexity of this topic and the need to better understand the potential effect of the underlying psychiatric diagnosis. Continued evaluation of the association between maternal use of SSRIs and congenital malformations is warranted, and there is a pressing need for new studies on the effects of individual SSRIs (and their dosage) on system-specific malformations, specifically in women with underlying psychiatric diagnosis. The accumulated evidence suggests a generally small risk of congenital malformations and argues against a substantial teratogenic effect of SSRIs. Caution is advisable in making decisions about whether to continue or stopping treatment with SSRIs during pregnancy. Stopping treatment in mothers with major depression could be more harmful for the infant than continuing use of SSRIs. This information could be helpful for pregnant women and their healthcare providers to make more informed decisions about treatment.

\section{Additional files}

Additional file 1: Table S1. Characteristics of prior meta-analyses of selective serotonin reuptake inhibitors (SSRIs) use in pregnancy and congenital malformations. (DOC $816 \mathrm{~kb}$ )

Additional file 2: Appendix 1. Search strategy. (DOCX 26 kb)

Additional file 3: Table S1. EUBOCAT Guide 1.3, ICD-10, and ICD-9 codes used to identify and define congenital malformations. Table S2. Characteristics of cohort studies of selective serotonin reuptake inhibitors (SSRIs) use in first-trimester and congenital malformations. Table S3. Risk of bias of included reports from cohort studies as assessed with the Newcastle-Ottawa scale. Table S4. Exposure to selective serotonin reuptake inhibitors (SSRIs) during the first trimester of pregnancy and risk of congenital malformations in infants: results of meta-analyses. Table S5. Exposure to citalopram during the first trimester of pregnancy and risk of congenital malformations in infants: results of meta-analyses. Table S6. Exposure to fluoxetine during the first trimester of pregnancy and risk of congenital malformations in infants: results of meta-analyses. Table S7. Exposure to paroxetine during the first trimester of pregnancy and risk of congenital malformations in infants: results of meta-analyses. Table S8. Exposure to sertraline during the first trimester of pregnancy and risk of congenital malformations in infants: results of meta-analyses. Table S9. Exposure to escitalopram during the first trimester of pregnancy and risk of congenital malformations in infants: results of meta-analyses. Table S10. Exposure to fluvoxamine during the first trimester of pregnancy and risk of congenital malformations in infants: results of meta-analyses. Table S11. Subgroup analysis of selective serotonin reuptake inhibitors (SSRIs) and risk of congenital malformations in infants: results of meta-analyses. Table S12. Subgroup analysis of citalopram and risk of congenital malformations in infants: results of meta-analyses. Table S13. Subgroup analysis of fluoxetine and risk of congenital malformations in infants: results of meta-analyses. Table S14. Subgroup analysis of paroxetine and risk of congenital malformations in infants: results of meta-analyses. Table S15. Subgroup analysis of sertraline and risk of congenital malformations in infants: results of meta-analyses. (DOC $1162 \mathrm{~kb}$ )

Additional file 4: Figure S1. Risk of major congenital anomalies in infants, according to maternal exposure to citalopram. (TIF $1083 \mathrm{~kb}$ )

Additional file 5: Figure S2. Risk of congenital heart defects in infants, according to maternal exposure to citalopram. (TIF 1123 kb)

Additional file 6: Figure S3. Risk of major congenital anomalies in infants, according to maternal exposure to fluoxetine. (TIF $1141 \mathrm{~kb}$ )

Additional file 7: Figure S4. Risk of congenital heart defects in infants, according to maternal exposure to fluoxetine. (TIF $1177 \mathrm{~kb}$ )

Additional file 8: Figure S5. Risk of major congenital anomalies in infants, according to maternal exposure to paroxetine. (TIF $1135 \mathrm{~kb}$ )

Additional file 9: Figure S6. Risk of congenital heart defects in infants, according to maternal exposure to paroxetine. (TIF 1244 kb)

Additional file 10: Figure S7. Risk of major congenital anomalies in infants, according to maternal exposure to sertraline. (TIF 1112 kb)

Additional file 11: Figure S8. Risk of congenital heart defects in infants, according to maternal exposure to sertraline. (TIF 1185 kb)

\section{Abbreviations}

ASD: Atrial septal defect; CHD: Congenital heart defect; Cls: Confidence intervals; EUROCAT: European Surveillance of Congenital Anomalies; MCAs: Major congenital anomalies; RR: Relative risk; RVOTD: Right ventricular outflow tract defect; SSRIs: Selective serotonin reuptake inhibitors; VSD: Ventricular septal defect

\section{Acknowledgements}

We would like to thank BioMed Proofreading for English proofreading.

Funding

This study was funded by National Key R\&D Program of China (no. 2017 YFC0907400 to Y-HZ); the Science and Technology Project of Liaoning Province (no. 2013225079 to Y-HZ); the Natural Science Foundation of China 
(no. 81602918 to Qi-Jun Wu), the Doctoral Start-up Foundation of Liaoning Province (no. 201501007 to Qi-Jun Wu), the Younger research fund of Shengjing Hospital (grant 2014sj09 to Qi-Jun Wu), and the Outstanding Youth Foundation of China Medical University (no. YQ20170002 to Qi-Jun Wu). The funders had no role in the study design, data collection, data analysis and interpretation, or the content of the final manuscript.

\section{Availability of data and materials}

The datasets used and/or analyzed during the current study are available from the corresponding author on reasonable request.

\section{Authors' contributions}

YG, Q-JW, and Y-HZ designed the study and formulated the clinical question S-YG and CS performed the literature search and, with Q-JW, reviewed the search results for study inclusion. T-NZ, Z-QS, and S-YG designed the data extraction form and extracted the data. All authors collected, managed, and analyzed the data. S-YG drafted the manuscript. All authors prepared, reviewed, revised, and approved the manuscript. Y-HZ had full access to all data in the study and is responsible for data integrity and the accuracy of data analysis. All authors read and approved the final manuscript.

\section{Ethics approval and consent to participate}

Not applicable.

\section{Consent for publication}

Not applicable.

\section{Competing interests}

The authors declare that they have no competing interests.

\section{Publisher's Note}

Springer Nature remains neutral with regard to jurisdictional claims in published maps and institutional affiliations.

\section{Author details}

${ }^{1}$ Department of Clinical Epidemiology, Shengjing Hospital of China Medical University, No. 36, San Hao Street, Shenyang, Liaoning, China. ${ }^{2}$ Department of Pediatrics, Shengjing Hospital of China Medical University, Shenyang, China. ${ }^{3}$ Department of Obstetrics and Gynecology, Shengjing Hospital of China Medical University, Shenyang, China.

Received: 29 June 2018 Accepted: 12 October 2018

\section{Published online: 12 November 2018}

\section{References}

1. Ornoy A, Koren G. Selective serotonin reuptake inhibitors in human pregnancy: on the way to resolving the controversy. Semin Fetal Neonatal Med. 2014;19(3):188-94.

2. Berard A, Zhao J, Sheehy O. Antidepressant use during pregnancy and the risk of major congenital malformations in a cohort of depressed pregnant women: an updated analysis of the Quebec Pregnancy Cohort. BMJ Open. 2017;7:e0133721.

3. Jimenez-Solem E, Andersen JT, Petersen M, Broedbaek K, Andersen NL, Torp-Pedersen C, et al. Prevalence of antidepressant use during pregnancy in Denmark, a nation-wide cohort study. PLoS One. 2013;8(4):e63034.

4. Taouk LH, Matteson KA, Stark LM, Schulkin J. Prenatal depression screening and antidepressant prescription: obstetrician-gynecologists' practices, opinions, and interpretation of evidence. Arch Womens Ment Health. 2018; 21(1):85-91.

5. Liu Y, Zhou X, Zhu D, Chen J, Qin B, Zhang Y, et al. Is pindolol augmentation effective in depressed patients resistant to selective serotonin reuptake inhibitors? A systematic review and meta-analysis. Hum Psychopharmacol. 2015;30(3):132-42.

6. Hendrick V, Stowe ZN, Altshuler LL, Hwang S, Lee E, Haynes D. Placental passage of antidepressant medications. Am J Psychiatry. 2003;160(5):993-6.

7. Laine K, Heikkinen T, Ekblad U, Kero P. Effects of exposure to selective serotonin reuptake inhibitors during pregnancy on serotonergic symptoms in newborns and cord blood monoamine and prolactin concentrations. Arch Gen Psychiatry. 2003;60(7):720-6.
8. Sadler TW. Selective serotonin reuptake inhibitors (SSRIs) and heart defects: potential mechanisms for the observed associations. Reprod Toxicol. 2011; 32(4):484-9.

9. U.S Food and Drug Administration (FDA). Public Health Advisory: Paroxetine 2005. https://wayback.archive-it.org/7993/20170112033310/http://www.fda. gov/Drugs/DrugSafety/PostmarketDrugSafetyInformationforPatients andProviders/ucm051731.htm. Accessed 27 Aug 2018.; 2018.

10. Nembhard WN, Tang X, Hu Z, MacLeod S, Stowe Z, Webber D. Maternal and infant genetic variants, maternal periconceptional use of selective serotonin reuptake inhibitors, and risk of congenital heart defects in offspring: population based study. BMJ. 2017;356:j832.

11. Kang HH, Ahn KH, Hong SC, Kwon BY, Lee EH, Lee JS, et al. Association of citalopram with congenital anomalies: a meta-analysis. Obstet Gynecol Sci. 2017;60(2):145-53.

12. Selmer $R$, Haglund B, Furu $K$, Andersen $M$, Nørgaard $M$, Zoëga $H$, et al. Individual-based versus aggregate meta-analysis in multi-database studies of pregnancy outcomes: the Nordic example of selective serotonin reuptake inhibitors and venlafaxine in pregnancy. Pharmacoepidem DR S. 2016; 25(10):1160-9.

13. Kowalik E, Ward K, Ye Y. SSRI use in pregnancy and congenital heart defects: a metaanalysis of population-based cohort studies. Pharmacotherapy. 2016;36(12):e302.

14. Wang S, Yang L, Wang L, Gao L, Xu B, Xiong Y. Selective Serotonin Reuptake Inhibitors (SSRIs) and the Risk of Congenital Heart Defects: A Meta-Analysis of Prospective Cohort Studies. J Am Heart Assoc. 2015;4(5):e001681.

15. Myles N, Newall H, Ward H, Large M. Systematic meta-analysis of individual selective serotonin reuptake inhibitor medications and congenital malformations. Aust NZ J Psychiat. 2013;47(11):1002-12.

16. Painuly N, Painuly $R$, Heun $R$, Sharan P. Risk of cardiovascular malformations after exposure to paroxetine in pregnancy: meta-analysis. Psychiatrist. 2013; 37(6):198-203.

17. Riggin L, Frankel Z, Moretti M, Pupco A, Koren G. The fetal safety of fluoxetine: a systematic review and meta-analysis. Journal of obstetrics and gynaecology Canada. JOGC. 2013;35(4):362-9.

18. Yan Y, Cheng Y, Crowe B, Chhabra-Khanna R, Camporeale A, Marangell L. First trimester fluoxetine use and major malformations: a meta-analysis of epidemiological studies. Pharmacoepidem DR S. 2013;22:168-9.

19. Nikfar S, Rahimi R, Hendoiee N, Abdollahi M. Increasing the risk of spontaneous abortion and major malformations in newborns following use of serotonin reuptake inhibitors during pregnancy: a systematic review and updated meta-analysis. Daru. 2012;20:75.

20. Wurst KE, Poole C, Ephross SA, Olshan AF. First trimester paroxetine use and the prevalence of congenital, specifically cardiac, defects: a meta-analysis of epidemiological studies. Birth Defects Res Part A Clin Mol Teratol. 2010;88(3): 159-70.

21. O'Brien L, Einarson TR, Sarkar M, Einarson A, Koren G. Does paroxetine cause cardiac malformations? J Obstet Gynaecol Can. 2008;30(8):696-701.

22. Bar-Oz B, Einarson T, Einarson A, Boskovic R, O'Brien L, Malm H, et al. Paroxetine and congenital malformations: meta-analysis and consideration of potential confounding factors. Clin Ther. 2007;29(5):918-26.

23. Addis A, Koren G. Safety of fluoxetine during the first trimester of pregnancy: a meta-analytical review of epidemiological studies. Psychol Med. 2000;30(1):89-94.

24. Zhang TN, Gao SY, Shen ZQ, Li D, Liu CX, Lv HC, et al. Use of selective serotonin-reuptake inhibitors in the first trimester and risk of cardiovascularrelated malformations: a meta-analysis of cohort studies. Sci Rep. 2017;7: 43085.

25. Shen ZQ, Gao SY, Li SX, Zhang TN, Liu CX, Lv HC, et al. Sertraline use in the first trimester and risk of congenital anomalies: a systemic review and metaanalysis of cohort studies. Brit J Clin Pharmaco. 2017;83(4):909-22.

26. Gao SY, Wu QJ, Zhang TN, Shen ZQ, Liu CX, Xu X, et al. Fluoxetine and congenital malformations: a systematic review and meta-analysis of cohort studies. Brit J Clin Pharmaco. 2017;83(10):2134-47.

27. Bérard A, lessa N, Chaabane S, Muanda FT, Boukhris T, Zhao JP. The risk of major cardiac malformations associated with paroxetine use during the first trimester of pregnancy: a systematic review and meta-analysis. Brit J Clin Pharmaco. 2016;81(4):589-604.

28. Grigoriadis S, VonderPorten EH, Mamisashvili L, Roerecke M, Rehm J, Dennis $\mathrm{CL}$, et al. Antidepressant exposure during pregnancy and congenital malformations: is there an association? A systematic review and metaanalysis of the best evidence. J Clin Psychiat. 2013;74(4):e293-308. 
29. Reefhuis J, Devine O, Friedman JM, Louik C, Honein MA. Specific SSRIs and birth defects: bayesian analysis to interpret new data in the context of previous reports. BMJ-Brit Med J. 2015;351:h3190.

30. Nishigori H, Obara T, Nishigori T, Mizuno S, Metoki H, Hoshiai T, et al. Selective serotonin reuptake inhibitors and risk of major congenital anomalies for pregnancies in Japan: a nationwide birth cohort study of the Japan Environment and Children's Study. Congenit Anom. 2017;57(3):72-8.

31. Jordan S, Morris JK, Davies Gl, Tucker D, Thayer DS, Luteijn JM, et al. Selective Serotonin Reuptake Inhibitor (SSRI) antidepressants in pregnancy and congenital anomalies: Analysis of linked databases in Wales, Norway and Funen, Denmark. Plos One. 2016;11(12):e0165122.

32. Petersen I, Evans SJ, Gilbert R, Marston L, Nazareth I. Selective serotonin reuptake inhibitors and congenital heart anomalies: comparative cohort studies of women treated before and during pregnancy and their children. J Clin Psychiat. 2016;77(1):e36-42.

33. Malm H, Sourander A, Gissler M, Gyllenberg D, Hinkka-Yli-Salomäki S, McKeague IW, et al. Pregnancy complications following prenatal exposure to SSRIs or maternal psychiatric disorders: results from population-based national register data. AM J Psychiat. 2015;172(12):1224-32.

34. Furu K, Kieler H, Haglund B, Engeland A, Selmer R, Stephansson O, et al. Selective serotonin reuptake inhibitors and venlafaxine in early pregnancy and risk of birth defects: population based cohort study and sibling design. BMJ. 2015;350:h1798.

35. Knudsen TM, Hansen AV, Garne E, Andersen AMN. Increased risk of severe congenital heart defects in offspring exposed to selective serotoninreuptake inhibitors in early pregnancy - an epidemiological study using validated EUROCAT data. BMC Pregnancy Childbirth. 2014;14(1):333.

36. Margulis AV, Abou-Ali A, Strazzeri MM, Ding Y, Kuyateh F, Frimpong EY, et al. Use of selective serotonin reuptake inhibitors in pregnancy and cardiac malformations: a propensity-score matched cohort in CPRD. Pharmacoepidem DR S. 2013;22(9):942-51.

37. Jimenez-Solem E, Andersen JT, Petersen M, Broedbaek K, Jensen JK, Afzal S, et al. Exposure to selective serotonin reuptake inhibitors and the risk of congenital malformations: A nationwide cohort study. BMJ Open. 2012;2(3):e001148.

38. Nordeng H, Van Gelder MMHJ, Spigset O, Koren G, Einarson A, EberhardGran M. Pregnancy outcome after exposure to antidepressants and the role of maternal depression: results from the Norwegian mother and child cohort study. J Clin Psychopharm. 2012;32(2):186-94.

39. Malm H, Artama M, Gissler M, Ritvanen A. Selective serotonin reuptake inhibitors and risk for major congenital anomalies. Obstet Gynecol. 2011; 118(1):111-20

40. Colvin L, Slack-Smith L, Stanley FJ, Bower C. Dispensing patterns and pregnancy outcomes for women dispensed selective serotonin reuptake inhibitors in pregnancy. Birth Defects Res Part A Clin Mol Teratol. 2011; 91(4):268.

41. Petersen I, Gilbert R, Evans S, Marston L, Nazareth I. SSRI and risk of congenital cardiac abnormalities. Pharmacoepidem DR S. 2010;19:S211.

42. Kornum JB, Nielsen RB, Pedersen L, Mortensen PB, Norgaard M. Use of selective serotonin-reuptake inhibitors during early pregnancy and risk of congenital malformations: updated analysis. Clin Epidemiol. 2010;2:29-36.

43. Pedersen LH, Henriksen TB, Vestergaard M, Olsen J, Bech BH. Selective serotonin reuptake inhibitors in pregnancy and congenital malformations: population based cohort study. BMJ. 2009;339:b3569.

44. Merlob P, Birk E, Sirota L, Linder N, Berant M, Stahl B, et al. Are selective serotonin reuptake inhibitors cardiac teratogens? Echocardiographic screening of newborns with persistent heart murmur. Birth Defects Res Part A Clin Mol Teratol. 2009;85(10):837-41.

45. Diav-Citrin O, Shechtman S, Weinbaum D, Wajnberg R, Avgil M, Di

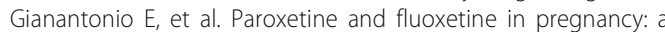
prospective, multicentre, controlled, observational study. Brit J Clin Pharmaco. 2008;66(5):695-705

46. Kallen BA, Otterblad OP. Maternal use of selective serotonin re-uptake inhibitors in early pregnancy and infant congenital malformations. Birth Defects Res A Clin Mol Teratol. 2007;79(4):301-8.

47. Vial T, Cournot MP, Bernard N, Carlier P, Jonville-Bero AP, Jean-Pastor MJ, et al. Paroxetine and congenital malformations: a prospective comparative study. Drug Saf. 2006;29(10):970.

48. Grote NK, Bridge JA, Gavin AR, Melville JL, lyengar S, Katon WJ. A meta-analysis of depression during pregnancy and the risk of preterm birth, low birth weight, and intrauterine growth restriction. Arch Gen Psychiatry. 2010;67(10):1012-24.
49. Szegda K, Markenson G, Bertone-Johnson ER, Chasan-Taber L. Depression during pregnancy: a risk factor for adverse neonatal outcomes? A critical review of the literature. J Matern Fetal Neonatal Med. 2014;27(9):960-7.

50. Ogunyemi D, Jovanovski A, Liu J, Friedman P, Sugiyama N, Creps J, et al. The contribution of untreated and treated anxiety and depression to prenatal, intrapartum, and neonatal outcomes. AJP Rep. 2018;8(3):e146-57.

51. Pedersen $\mathrm{LH}$. The risks associated with prenatal antidepressant exposure: time for a precision medicine approach. Expert Opin Drug Saf. 2017;16(8): 915-21.

52. Susser LC, Sansone SA, Hermann AD. Selective serotonin reuptake inhibitors for depression in pregnancy. Am J Obstet Gynecol. 2016;215(6):722-30.

53. Koren $\mathrm{G}$, Nordeng $\mathrm{H}$. Antidepressant use during pregnancy: the benefit-risk ratio. Am J Obstet Gynecol. 2012;207(3):157-63.

54. Moher D, Liberati A, Tetzlaff J, Altman DG. Preferred reporting items for systematic reviews and meta-analyses: the PRISMA statement. BMJ. 2009; 339:b2535.

55. Huybrechts KF, Palmsten K, Avorn J, Cohen LS, Holmes LB, Franklin JM, et al. Antidepressant use in pregnancy and the risk of cardiac defects. N Engl J Med. 2014;370(25):2397-407.

56. Davis RL, Rubanowice D, McPhillips H, Raebel MA, Andrade SE, Smith D, et al. Risks of congenital malformations and perinatal events among infants exposed to antidepressant medications during pregnancy. Pharmacoepidemiol Drug Saf. 2007;16(10):1086-94

57. Chambers CD, Johnson KA, Dick LM, Felix RJ, Jones KL. Birth outcomes in pregnant women taking fluoxetine. N Engl J Med. 1996;335(14):1010-5.

58. Vasilakis-Scaramozza C, Aschengrau A, Cabral H, Jick SS. Antidepressant use during early pregnancy and the risk of congenital anomalies. Pharmacotherapy. 2013;33(7):693-700.

59. Klieger-Grossmann C, Weitzner B, Panchaud A, Pistelli A, Einarson T, Koren G, et al. Pregnancy outcomes following use of escitalopram: a prospective comparative cohort study. J Clin Pharmacol. 2012;52(5):766-70.

60. Einarson A, Choi J, Einarson TR, Koren G. Incidence of major malformations in infants following antidepressant exposure in pregnancy: results of a large prospective cohort study. Can J Psychiatr. 2009;54(4):242-6.

61. Oberlander TF, Warburton W, Misri S, Riggs W, Aghajanian J, Hertzman C. Major congenital malformations following prenatal exposure to serotonin reuptake inhibitors and benzodiazepines using population-based health data. Birth Defects Res Part B Dev Reprod Toxicol. 2008;83(1):68-76.

62. Wells GA, Shea BJ, O'Connell D, Peterson J, Welch V, Losos M, et al. The Newcastle-Ottawa scale (NOS) for assessing the quality of non-randomized studies in meta-analysis. Appl Eng Agric. 2014;18(6):727-34.

63. Odutayo A, Wong CX, Hsiao AJ, Hopewell S, Altman DG, Emdin CA. Atrial fibrillation and risks of cardiovascular disease, renal disease, and death: systematic review and meta-analysis. BMJ. 2016;354:i4482.

64. Bérard A, Zhao JP, Sheehy O. Sertraline use during pregnancy and the risk of major malformations. Am J Obstet Gynecol. 2015;212(6):791-5.

65. Hamling J, Lee $P$, Weitkunat $R$, Ambuhl M. Facilitating meta-analyses by deriving relative effect and precision estimates for alternative comparisons from a set of estimates presented by exposure level or disease category. Stat Med. 2008;27(7):954-70.

66. Einarson A, Pistelli A, DeSantis M, Malm H, Paulus WD, Panchaud A, et al. Evaluation of the risk of congenital cardiovascular defects associated with use of paroxetine during pregnancy. AM J Psychiat. 2008;165(6):749-52.

67. Rothman KJ. Development DD. Modern Epidemiology. 3rd ed; 2014

68. Dersimonian R, Laird N. Meta-analysis in clinical trials. Control Clin Trials. 1986;7(3):177.

69. Higgins JP, Thompson SG, Deeks JJ, Altman DG. Measuring inconsistency in meta-analyses. BMJ. 2003;327(7414):557-60.

70. Begg CB, Mazumdar M. Operating characteristics of a rank correlation test for publication bias. Biometrics. 1994;50(4):1088-101.

71. Egger M, Davey SG, Schneider M, Minder C. Bias in meta-analysis detected by a simple, graphical test. BMJ. 1997;315(7109):629-34.

72. Ban L, Gibson JE, West J, Fiaschi L, Sokal R, Smeeth L, et al. Maternal depression, antidepressant prescriptions, and congenital anomaly risk in offspring: a population-based cohort study. Bjog-Int J Obstet GY. 2014; 121(12):1471-81.

73. Sari $Y$, Zhou FC. Serotonin and its transporter on proliferation of fetal heart cells. Int J Dev Neurosci. 2003;21(8):417-24.

74. Sit DK, Perel JM, Helsel JC, Wisner KL. Changes in antidepressant metabolism and dosing across pregnancy and early postpartum. J Clin Psychiatry. 2008;69(4):652-8. 
75. Yavarone MS, Shuey DL, Tamir H, Sadler TW, Lauder JM. Serotonin and cardiac morphogenesis in the mouse embryo. Teratology. 1993;47(6):573-84.

76. Choi DS, Kellermann O, Richard S, Colas JF, Bolanos-Jimenez F, Tournois C, et al. Mouse 5-HT2B receptor-mediated serotonin trophic functions. Ann N Y Acad Sci. 1998;861:67-73.

77. Gentile S. Early pregnancy exposure to selective serotonin reuptake inhibitors, risks of major structural malformations, and hypothesized teratogenic mechanisms. Expert Opin Drug Metab Toxicol. 2015;11(10):1585-97.

78. Carmi R, Gohar J, Meizner I, Katz M. Spontaneous abortion--high risk factor for neural tube defects in subsequent pregnancy. Am J Med Genet. 1994; 51(2):93-7.

79. Bukowski R, Carpenter M, Conway D, Coustan D, Dudley DJ, Goldenberg RL, et al. Causes of death among stillbirths. Jama-J Am Med Assoc. 2011; 306(22):2459-68.

80. Ehrenstein V, Sorensen HT, Bakketeig LS, Pedersen L. Medical databases in studies of drug teratogenicity: methodological issues. Clin Epidemiol. 2010;2:37-43

81. Tuccori M, Montagnani S, Testi A, Ruggiero E, Mantarro S, Scollo C, et al. Use of selective serotonin reuptake inhibitors during pregnancy and risk of major and cardiovascular malformations: an update. Postgrad Med. 2010; 122(4):49-65.

82. Alwan S, Friedman JM. Safety of selective serotonin reuptake inhibitors in pregnancy. CNS Drugs. 2009;23(6):493-509.

83. Alwan S, Friedman JM, Chambers C. Safety of selective serotonin reuptake inhibitors in pregnancy: a review of current evidence. CNS Drugs. 2016; 30(6):499-515

84. Alwan S, Reefhuis J, Rasmussen SA, Olney RS, Friedman JM. Use of selective serotonin-reuptake inhibitors in pregnancy and the risk of birth defects. N Engl J Med. 2007;356(26):2684-92.

Ready to submit your research? Choose BMC and benefit from:

- fast, convenient online submission

- thorough peer review by experienced researchers in your field

- rapid publication on acceptance

- support for research data, including large and complex data types

- gold Open Access which fosters wider collaboration and increased citations

- maximum visibility for your research: over $100 \mathrm{M}$ website views per year

At $\mathrm{BMC}$, research is always in progress.

Learn more biomedcentral.com/submissions 